\title{
Energy-Based Seismic Design Method for EBFs Based on Hysteretic Energy Spectra and Accumulated Ductility Ratio Spectra
}

\author{
Cuiling $\mathrm{Ma}^{1,2}$ \\ ${ }^{1}$ College of Civil and Transportation Engineering, Hohai University, Nanjing 210098, China \\ ${ }^{2}$ Department of Civil Engineering, Hefei University, Hefei 230601, China \\ Correspondence should be addressed to Cuiling Ma; ling3701@163.com
}

Received 14 June 2019; Revised 22 October 2019; Accepted 30 October 2019; Published 19 November 2019

Academic Editor: Rosario Montuori

Copyright (c) 2019 Cuiling Ma. This is an open access article distributed under the Creative Commons Attribution License, which permits unrestricted use, distribution, and reproduction in any medium, provided the original work is properly cited.

In the case of far field earthquakes, structural failure often results from accumulated damage caused by cyclic effects and gradual accumulation of energy. This paper proposes an energy-based seismic design method for steel eccentrically braced frames (EBFs) with two shear links at every story according to the energy balance concept. The proposed method is theoretically supported by hysteretic energy spectra and accumulated ductility ratio spectra according to the Chinese soil classification. Furthermore, the method can be used to clarify the relationship between cumulative hysteretic energy and one-way pushover energy. For developing the method, it is assumed that all the hysteretic energy is dissipated by the shear links, column bases, and beam ends of the frames at both sides. Therefore, the parts outside the links, including beam segments, braces, and columns, are specially designed to perform elastically during an earthquake. Furthermore, a V-scheme steel EBF with ten stories and three spans is designed. The seismic performances of the designed structure, such as story drift and energy dissipation, are evaluated by nonlinear static analysis and time-history analysis. Finally, the reliability and accuracy of the proposed seismic design method are validated.

\section{Introduction}

As for conventional seismic analysis of structure, it is usually conducted on the basis of the strength and displacement without considering the progressive damage to the structure caused by the duration of ground motion. Compared with strength- or displacement-based seismic designs, an energybased seismic design is preferable as it can include more ground motion characteristics.

The concept of energy-based design was originally introduced by Housner [1] and has attracted extensive attention from researchers and engineers worldwide. Ozsarac et al. [2] analyzed the energy-based responses of simple structural systems by using a large set of simulated ground motion records and showed that energy is a relatively stable parameter when compared with other response parameters. Chao and Goel [3] suggested that a controlled structure is mainly dependent on three major factors, namely, the distribution of design lateral force, the predictable global yield mechanism, and the target drift. In addition, Leelataviwat et al. [4] proposed a simplified energy-based plastic design method for moment steel frames. In addition, both the pseudovelocity design spectrum and the earthquake input energy equations of elastic systems were employed to obtain the design base shear. Afterwards, this design method was further developed to be employed in the design of other structural systems. For example, Lee [5] presented a new design procedure based on inelastic analysis for momentresisting frames in severe seismic zones. Chao and Goel developed a seismic design method for steel concentric braced frames [6] and a performance-based plastic design for seismic-resistant special truss moment frames [7]. Kim et al. [8] proposed an energy-based seismic design procedure for framed structures with buckling-restrained braces (BRBs). The input seismic energy was estimated from a design spectrum, and the elastic and hysteretic energy was computed using the energy balance concept. The crosssectional area of braces required to meet a given target 
displacement was obtained by equating the energy demand to hysteretic energy dissipated by the BRBs. Sahoo and Chao [9] presented a performance-based plastic design (PBPD) methodology for the design of buckling-restrained braced frames (BRBFs). The design base shear was obtained on the basis of energy-work balance by using the preselected target drift and yield mechanism. Akbas et al. [10] proposed a performance-based design methodology for constructing regular moment-resisting steel frames with the collapse prevention standard. Mastrandrea and Piluso [11] presented a design methodology aiming at the development of a collapse mechanism of a global type for K-scheme eccentrically braced frames, accounting for second-order effects. Finally, the inelastic performances of EBFs by static and dynamic nonlinear analyses confirmed the achievement of the design goal. Montuori et al. [12] designed a number of moment-resisting frames-eccentrically braced frame (MRFEBF) dual systems with both theory of plastic mechanism control (TPMC) and Eurocode 8 and evaluated TPMC accuracy by means of pushover analyses. Afterwards, they investigated the influence of the bracing scheme [13] and link configuration [14] on the seismic performances of MRFEBFs dual systems. The four different bracing schemes included K-scheme, D-scheme, V-scheme, and Y-scheme. The seismic performances have been analyzed by means of incremental dynamic analyses at last. Dell'Aglio et al. designed several steel moment-resisting frames (MR frames) by means of both the performance-based plastic design (PBPD) approach and TPMC [15] and proposed a new refined PBPD, considering second-order effects, for steel momentresisting frames [16]. Finally, the seismic performances of such MR frames have been investigated by both pushover and dynamic nonlinear analyses.

Choi and Kim [17] and Sun et al. [18] suggested calculating the accumulated plastic deformation of structures by employing the accumulated ductility ratio spectra. They also revealed the relationship between the accumulated hysteretic energy and the hysteretic energy of monotonous sideway structures. Furthermore, Choi and Kim [19] designed three frame structures with buckling-restrained braces (BRBs) by employing the energy balance concept after the construction of a hysteretic energy spectrum and an accumulated ductility spectrum. Using the normalized hysteretic energy spectrum and the accumulated ductility spectrum, Sun et al. [18] developed an energy-based seismic design method for steel plate shear walls (SPSWs). Kharmale and Ghosh [20] proposed a performance-based plastic design (PBPD) method for SPSW systems with rigid beam-tocolumn connections; this method sets a specific ductility demand and a preferred yield mechanism as its performance targets. Xiong et al. [21] presented a PBPD methodology based on the energy-work balance concept for steel concentrically braced frames. Mezgebo and Lui [22] proposed a procedure for designing steel moment frames by utilizing seismic hysteretic energy spectra.

However, most of the abovementioned researches were limited to moment-resisting frames, steel concentrically braced frames, steel frames of special truss moment, and SPSWs, and they were inapplicable to steel EBFs with two shear links at every story. Moreover, all the mentioned energy spectra were developed on the basis of non-Chinese site classification and are inapplicable in China.

EBFs are deemed as excellent structures to resist earthquakes as they colligate the ductility of moment frames with the stiffness of braced frames. In this paper, hysteretic energy spectra and accumulated ductility ratio spectra established according to the Chinese site classification are used to propose an energy-based seismic design method for $\mathrm{V}$-scheme EBFs. Moreover, a ten-story three-span V-EBF is designed, and its seismic behavior is evaluated.

\section{Hysteretic Energy Spectra and Accumulated Ductility Ratio Spectra}

2.1. Hysteretic Energy Spectra. Bruneau and Wang [23] stated that it is more rational to calculate seismic input energy by using the relative energy equation. The motion equation for an inelastic single-degree-of-freedom (SDOF) system subjected to the unidirectional horizontal ground motions at given times is as follows:

$$
m \ddot{x}+c \dot{x}+f_{\mathrm{s}}=-m \ddot{x}_{\mathrm{g}},
$$

where $m$ denotes the mass, $c$ denotes the viscous damping coefficient, $f_{\mathrm{s}}$ denotes the restoring force, $x$ denotes the relative displacement relative to ground, $\dot{x}$ and $\ddot{x}$ denote the velocity and acceleration of the mass relative to ground, respectively, and $\ddot{x}_{\mathrm{g}}$ denotes ground acceleration.

Through integration of an earthquake's whole duration, the energy equation can be obtained as follows:

$$
\int_{0}^{t} m \ddot{x} \dot{x} \mathrm{~d} t+\int_{0}^{t} c \ddot{x} \dot{x} \mathrm{~d} t+\int_{0}^{t} f_{\mathrm{s}} \dot{x} \mathrm{~d} t=-\int_{0}^{t} m \ddot{x}_{\mathrm{g}} \dot{x} \mathrm{~d} t
$$

where $t$ is the time.

Equation (2) can be expressed as

$$
E_{\mathrm{Kr}}+E_{\mathrm{D}}+E_{\mathrm{E}}+E_{\mathrm{H}}=E_{\mathrm{Ir}},
$$

where $E_{\mathrm{Kr}}$ is the kinetic energy, $E_{\mathrm{D}}$ is the energy dissipated by the viscous damping, $E_{\mathrm{E}}$ is the elastic strain energy within the SDOF system, $E_{\mathrm{H}}$ is the hysteretic energy dissipated by inelastic behavior, and $E_{\mathrm{Ir}}$ is the total input energy introduced by the earthquake.

Under a far field earthquake, structural failures usually result from accumulative damage because of gradual accumulation of the energy and cyclic effects. As a result, the accumulated hysteretic energy can be treated as a rational index for far field seismic damage. $E_{\mathrm{H}}$ can be expressed in terms of the equivalent velocity $V_{\mathrm{EH}}$ [24]:

$$
V_{\mathrm{EH}}=\sqrt{\frac{2 E_{\mathrm{H}}}{m}},
$$

where $m$ denotes the mass.

The equivalent velocity spectrum meeting the Chinese site classification was developed by $\mathrm{Ma}$ et al. [25]. Figure 1 shows the fitted spectral smooth curves.

The corresponding mathematical expressions are as follows: 


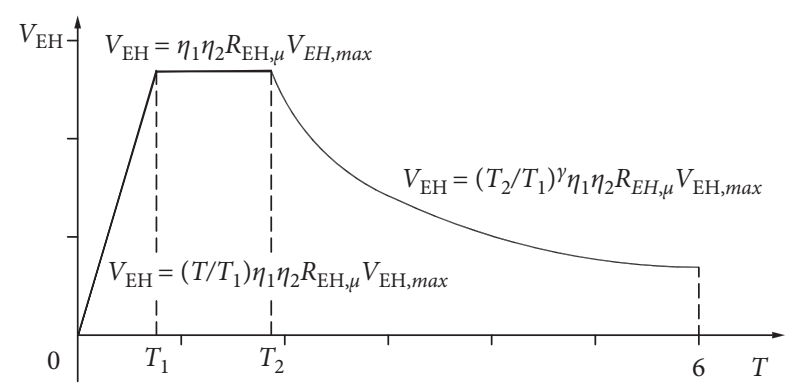

FIgURE 1: Three-segment model of equivalent velocity spectra of accumulated hysteretic energy.

$$
\begin{aligned}
& V_{\mathrm{EH}}=\left(\frac{T}{T_{1}}\right) \eta_{1} \eta_{2} R_{\mathrm{EH}, \mu} V_{\mathrm{EH}, \max }, \quad 0 \leq T \leq T_{1}, \\
& V_{\mathrm{EH}}=\eta_{1} \eta_{2} R_{\mathrm{EH}, \mu} V_{\mathrm{EH}, \max }, \quad T_{1} \leq T \leq T_{2}, \\
& V_{\mathrm{EH}}=\left(\frac{T_{2}}{T}\right)^{\gamma} \eta_{1} \eta_{2} R_{\mathrm{EH}, \mu} V_{\mathrm{EH}, \max , \quad} T_{2} \leq T \leq 6,
\end{aligned}
$$

where $T_{1}$ denotes the separation period between the horizontal segment and the rising segment, $T_{2}$ denotes the separation period between the declining segment and the horizontal segment (as shown in Figure 1), $\eta_{1}$ denotes the corresponding acceleration amplitude correction factor and is computed using equation (6), $\eta_{2}$ denotes the structural damping ratio correction factor and is computed using equation (7), $R_{\mathrm{EH}, \mu}$ denotes the correction factor of structural ductility and is computed using equation (8), $\gamma$ denotes the declining segment attenuation index and is computed using equation (9), and $V_{\mathrm{EH} \text {,max }}$ denotes the peak value of the equivalent velocity spectrum of accumulated hysteretic energy at a structural damping ratio $\zeta$ of 0.05 , an acceleration amplitude of $0.2 \mathrm{~g}$, a ductility factor $\mu$ of 2 , and a postyield stiffness ratio $p$ of 0.0 (as listed in Table 1).

$$
\eta_{1}=\frac{\ddot{x}_{\mathrm{g}}}{\ddot{x}_{0.2 \mathrm{~g}}},
$$

where $\ddot{x}_{0.2 \mathrm{~g}}$ denotes the acceleration amplitude corresponding to $V_{\mathrm{EH} \text {,max }}$.

$$
\eta_{2}=1+\frac{0.05-\zeta}{0.1+1.5 \zeta}
$$

where $\zeta$ denotes the structural damping ratio.

$$
R_{\mathrm{EH}, \mu}=1+\frac{\mu-2}{2.5+2 \mu},
$$

where $\mu$ denotes the structural ductility ratio.

$$
\gamma=\gamma_{1}+\frac{0.05-\zeta}{0.4+6 \zeta},
$$

where the values of $\gamma_{1}$, given in Table 1 , are associated with the site group and soil type.

2.2. Accumulated Ductility Ratio Spectra. Under a far field earthquake, the accumulative ductility of a structure
TABLE 1: Equivalent velocity spectrum parameters when the acceleration amplitude is $0.2 \mathrm{~g}$.

\begin{tabular}{lccccc}
\hline Soil type & Site group & $V_{\mathrm{EH}, \text { max }}(\mathrm{m} / \mathrm{s})$ & $T_{1}(\mathrm{~S})$ & $T_{2}(\mathrm{~S})$ & $\gamma_{1}$ \\
\hline \multirow{3}{*}{$\mathrm{I}_{0}$} & Group 1 & 0.14 & 0.09 & 0.38 & 0.28 \\
& Group 2 & 0.30 & 0.31 & 0.71 & 0.46 \\
& Group 3 & 0.52 & 0.73 & 2.28 & 0.31 \\
\hline \multirow{2}{*}{$\mathrm{I}_{1}$} & Group 1 & 0.18 & 0.12 & 0.42 & 0.32 \\
& Group 2 & 0.38 & 0.37 & 0.77 & 0.50 \\
& Group 3 & 0.58 & 0.77 & 2.34 & 0.35 \\
\hline \multirow{3}{*}{$\mathrm{II}$} & Group 1 & 0.24 & 0.20 & 0.45 & 0.3 \\
& Group 2 & 0.45 & 0.40 & 1.10 & 0.4 \\
& Group 3 & 0.65 & 0.95 & 2.2 & 0.2 \\
\hline \multirow{3}{*}{$\mathrm{III}$} & Group 1 & 0.30 & 0.20 & 1.0 & 0.35 \\
& Group 2 & 0.40 & 0.40 & 2.0 & 0.75 \\
& Group 3 & 0.75 & 1.20 & 4.70 & 0.82 \\
\hline \multirow{3}{*}{$\mathrm{IV}$} & Group 1 & 0.48 & 0.40 & 1.25 & 0.90 \\
& Group 2 & 0.55 & 0.60 & 1.20 & 1.00 \\
& Group 3 & 1.20 & 0.85 & 4.85 & 1.20 \\
\hline
\end{tabular}

resulting from the lateral irregular cyclic displacement can be represented by the accumulative ductility ratio $\left(N E_{\mathrm{H}, \mu}\right)$. Teran-Gilmore et al. [26] pointed out that the accumulative ductility ratio-the ratio of cumulative plastic displacement and the yield displacement of the structure-can be calculated using the following equation:

$$
N E_{\mathrm{H}, \mu}=\frac{E_{\mathrm{H}, \mu}}{F_{\mathrm{y}} \cdot \delta_{\mathrm{y}}},
$$

where $E_{\mathrm{H}, \mu}$ denotes the structural accumulative hysteretic energy under seismic effects, $F_{\mathrm{y}}$ denotes the structural yield strength, and $\delta_{\mathrm{y}}$ denotes the yield displacement of the structure.

On the basis of inelastic time-history analysis, $N E_{\mathrm{H}, \mu}$ for an SDOF system at a given natural time period and a constant ductility ratio can be obtained. Considering the soil types in China, $\mathrm{NE}_{\mathrm{H}, \mu}$ average values for 15 groups of ground motions with different $T, \zeta, \mu$, and $p$ values are selected. Then, equations (11)-(14) for the accumulated ductility ratio spectrum are proposed. The analysis also reveals that the effect of period is not apparent and can be neglected:

$$
\begin{aligned}
N E_{\mathrm{H}, \mu} & =\alpha \cdot \beta \cdot f(T, \zeta, \mu, p) \\
& =\alpha \cdot \beta \cdot f(\zeta) \cdot f(p) \cdot f(\mu), \\
f(\zeta) & =0.52 \zeta+0.75 \\
f(p) & =-6.2 p^{2}+4.0 p+0.856, \\
f(\mu) & =1.63 \mu^{2}+0.75 \mu-2.38
\end{aligned}
$$

where $\alpha$ denotes the effect factor for the site type, the values of which are $1.1,1.1,1.0,1.2$, and 1.3 for soil types $\mathrm{I}_{0}, \mathrm{I}_{1}, \mathrm{II}$, III, and IV, respectively, and $\beta$ denotes the effect factor for the site group, the values of which are 1.0, 1.1, and 1.0 for site groups 1, 2, and 3, respectively. 


\section{Energy-Based Design Approach for Steel EBFs}

3.1. Design Procedures. Using the proposed accumulated ductility ratio spectrum and accumulated hysteretic energy spectrum, an energy-based design approach for steel EBFs with a $\mathrm{V}$-scheme $(\mathrm{V}-\mathrm{EBF})$ is proposed as follows:

(1) Preselect the desirable plastic mechanism: Figure 2 shows a V-EBF subjected to design lateral forces in its maximum drift state. At the middle of the span, all the inelastic deformations are intended to be confined within the shear links in the form of shear yielding. Since the plastic hinges developed at the column bases are almost unavoidable in a rare earthquake, the desired global plastic mechanism for an EBF is formed by the yielding of the shear links and the plastic hinges at the column bases and beam ends of both side frames.

(2) Obtain preliminary design for each member and the first few vibration mode shapes and structural periods through modal analysis.

(3) Calculate the structural accumulative hysteretic energy demands by using the accumulated hysteretic energy spectra and the modal-energy-decomposition approach.

The accumulated hysteretic energy demand of the $\mathrm{V}$-EBF can be seen in Figure 2 that shows a V-EBF subjected to design lateral forces in its maximum drift state. At the middle of the span, all the inelastic deformations are intended to be confined within the shear links in the form of shear yielding. Since the plastic hinges developed at the column bases are almost unavoidable in a rare earthquake, the desired global plastic mechanism for an EBF is formed by the yielding of the shear links and the plastic hinges at the column bases and beam ends of the both side frames, obtained using equations (15)-(19). The right-hand side of equation (15) can be interpreted as denoting the modal-energy-decomposition approach, applicable for inelastic multidegree-of-freedom (MDOF) systems. Subsequently, satisfactory energy estimates are obtained [27]:

$$
\begin{aligned}
E_{\mathrm{h}(\mathrm{MDOF})} & =\frac{\sum_{j=1}^{N} E_{\mathrm{h}(\mathrm{MDOF}), j} \Gamma_{j}^{2}}{\sum_{j=1}^{N} X_{\text {mass }, j}}, \\
E_{\mathrm{h}(\mathrm{ESDOF}), j} & =\frac{1}{2} M_{j}^{*} V_{\mathrm{EH}, j}^{2}, \\
M_{j}^{*} & =\phi_{j}^{T} M \phi_{j}, \\
\Gamma_{j} & =\frac{\sum_{i=1}^{n} m_{i} \varphi_{i j}}{\sum_{i=1}^{n} m_{i} \varphi_{i j}^{2}},
\end{aligned}
$$

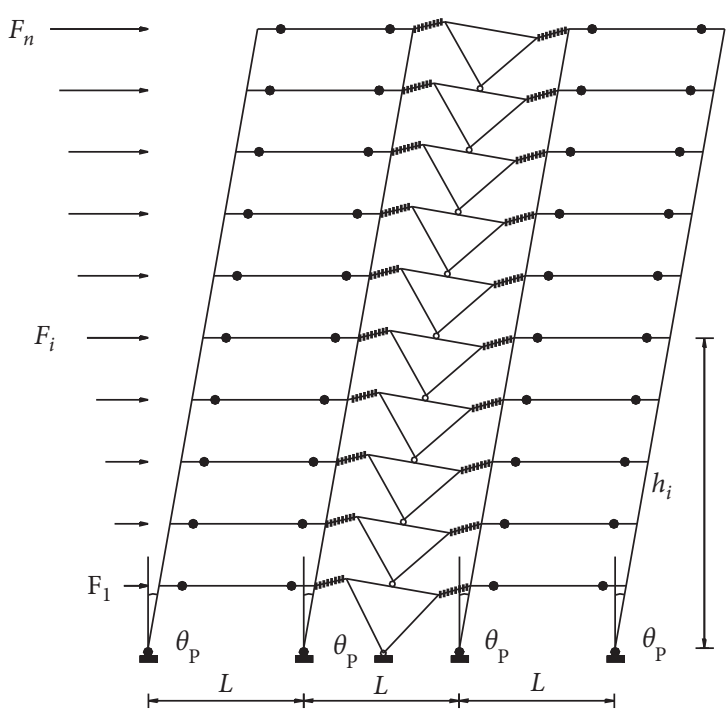

Figure 2: Desired plastic mechanism.

$$
X_{\text {mass }, j}=\frac{\left(\sum_{i=1}^{n} m_{i} \phi_{i j}\right)^{2}}{\left(\sum_{i=1}^{n} m_{i}\right)\left(\sum_{i=1}^{n} m_{i} \phi_{i j}^{2}\right)}
$$

where $E_{\mathrm{h}(\mathrm{MDOF})}$ denotes the total accumulated hysteretic energy demand of an MDOF and $E_{\mathrm{h}(\mathrm{ESDOF}), j}$ is the accumulated hysteretic energy demand of an equivalent SDOF system corresponding to the $j$ th mode; $M_{j}^{*}$ is the effective mass acquired through the $j$ th mode; $\Gamma_{j}$ is the modal participation factor of the $j$ th mode; $X_{\text {mass, } j}$ is the mass participation factor of the $j$ th mode; $V_{\mathrm{EH}, j}$ is the equivalent velocity of the SDOF system corresponding to the $j$ th mode; $\phi_{j}$ is the $j$ th mode with $n$ elements; $N$ is the total number of mode shapes, let $N=3$ for the $\mathrm{V}$-EBF; and $n$ is the total number of stories.

(4) Determine the distribution pattern of structural lateral forces: the design lateral forces are determined by utilizing the shear distribution factor $\beta_{i}$ obtained through nonlinear time-history analysis for steel EBFs [3]. $\beta_{i}$ is expressed as

$$
\begin{aligned}
& \beta_{i}=\frac{V_{i}}{V_{n}}=\left(\frac{\sum_{i}^{n} W_{i} h_{i}}{W_{n} h_{n}}\right)^{0.75 T^{-0.2}} \\
& F_{n}=V\left(\frac{W_{n} h_{n}}{\sum_{j=1}^{n} W_{j} h_{j}}\right)^{0.75 T^{-0.2}}, \\
& F_{i}=\left(\beta_{i}-\beta_{i+1}\right) F_{n}, \quad \text { when } i=n, \beta_{i+1}=0, \\
& V_{i}=\frac{\beta_{i}}{\beta_{1}} V
\end{aligned}
$$

where $\beta_{i}$ denotes the shear distribution factor at level $i$; $V$ is the design base shear; $F_{i}$ and $F_{n}$ denote the lateral 
forces applied at level $i$ and top level $n$, respectively; $V_{i}$ and $V_{n}$ denote the story shear forces at level $i$ and the top ( $n$ th) level, respectively; $W_{i}, W_{j}$, and $W_{n}$ denote the structural weight at levels $i, j$, and the top ( $n$ th) level, respectively; $h_{i}, h_{j}$, and $h_{n}$ denote the story height at the levels $i, j$, and roof from ground, respectively; and $T$ denotes the fundamental structural period.

(5) Calculate the design lateral force: the accumulated hysteretic demand $E_{\mathrm{h}(\mathrm{MDOF})}$ of the $\mathrm{V}$-scheme $\mathrm{EBF}$ is expressed as the external work done by the design lateral force:

$$
E_{\mathrm{h}(\mathrm{MDOF})}=\eta(1-p) \sum_{i=1}^{n} F_{i} \theta_{\mathrm{y}} h_{i} N E_{\mathrm{h}, \mu},
$$

where $\eta$ is the parameter of the pinching effect $(0.85$ for the $\mathrm{V}-\mathrm{EBF}$ ), $\theta_{\mathrm{y}}$ is the global yield drift angle (in radians), $N E_{\mathrm{h}, u}$ is the accumulated ductility ratio of the V-EBF, $p$ is the postyield stiffness, $F_{i}$ is the lateral force at the story level $i, h_{i}$ is the height of the story level $i$ from the ground, and $n$ is the total number of stories. By substituting equations (20)-(22) in equation (24), the value of $F_{n}$ is obtained:

$$
F_{n}=\frac{E_{\mathrm{h}(\mathrm{MDOF})}}{\eta(1-p) N E_{\mathrm{h}, \mu} \theta_{\mathrm{y}} \sum_{i=1}^{n}\left(\beta_{i}-\beta_{i+1}\right) h_{i}} .
$$

The story shear $F_{i}(i=1, \ldots, n)$ and $V_{i}$ are obtained using equations (22) and (23), respectively. Note that the story shear force and design lateral force required are associated with the distribution of lateral forces and the structural intended target ductility ratio.

(6) Perform proportioning of the link beam and members outside the links.

For the V-EBF, inelastic actions are intended to occur only in the shear links, column bases, and beam ends of both side frames. Under a rare earthquake, the distribution of shear link strength along the building height is consistent with the distribution of the story shear force. Hence, the shear distribution factor $\left(\beta_{i}\right)$ can be used to distribute the yielding of links along the V-EBF height.

According to Figure 2 and the principle of virtual work, equation (26) can be obtained by equating the external work to the internal work under a given link plastic rotation angle $\gamma_{\mathrm{p}}$ of the V-EBF (Figure 3):

$$
\begin{aligned}
\sum_{i=1}^{n} F_{i} h_{i} \theta_{\mathrm{p}}= & \sum_{i=1}^{n} 4 f_{y} W_{\mathrm{psbi}} \theta_{\mathrm{p}}+2 f_{y} W_{\mathrm{pmc}} \theta_{\mathrm{p}} \\
& +2 f_{y} W_{\mathrm{psc}} \theta_{\mathrm{p}}+\sum_{i=1}^{n} 2 \beta_{i} V_{\mathrm{ts}} \gamma_{\mathrm{p}} e .
\end{aligned}
$$

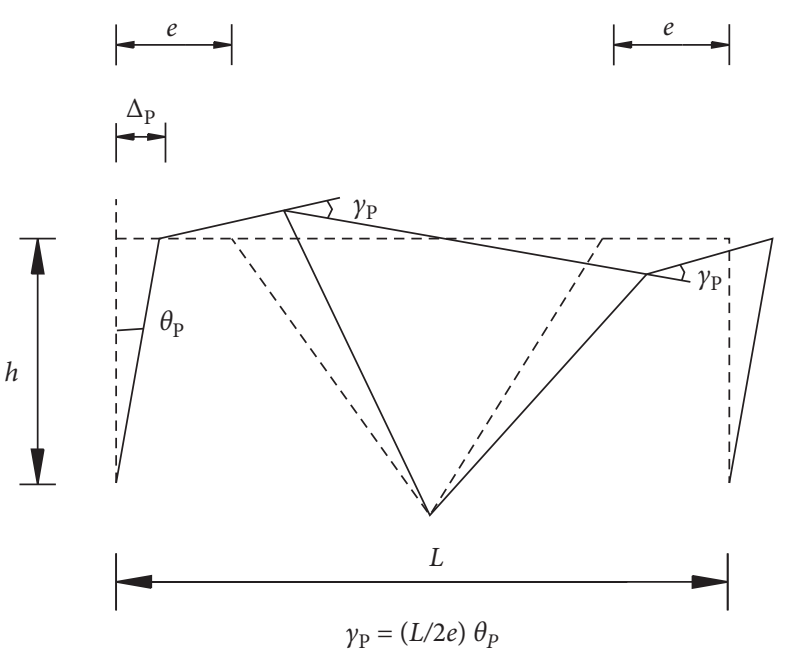

FIgURE 3: Link rotation angle of V-EBF.

Nonlinear time-history analysis reveals that only a small amount of energy, less than $2 \%$, is dissipated by the plastic hinges developed at the beam ends of both side frames. It is almost impossible that the beam ends yield at the same time. Therefore, for simplicity and obtaining more conservative results, the hysteretic energy of the beam ends in equation (26) can be neglected, and the equation can be expressed as

$$
\begin{aligned}
\sum_{i=1}^{n} F_{i} h_{i} \theta_{\mathrm{p}}= & 2 f_{\mathrm{y}} W_{\mathrm{pmc}} \theta_{\mathrm{p}}+2 f_{\mathrm{y}} W_{\mathrm{psc}} \theta_{\mathrm{p}} \\
& +\sum_{i=1}^{n} 2 \beta_{i} V_{\mathrm{ts}} \gamma_{\mathrm{p}} e, \\
V_{\mathrm{ts}}= & \frac{\sum_{i=1}^{n} F_{i} h_{i}-2 f_{\mathrm{y}}\left(W_{\mathrm{pmc}}+W_{\mathrm{psc}}\right)}{L \sum_{i=1}^{n} \beta_{i}},
\end{aligned}
$$

where $L$ is the span length; $e$ is the shear link length; $V_{\text {ts }}$ is the required shear strength of links at the top story, which is the only unknown term in equation (27); $\theta_{\mathrm{p}}$ is the V-EBF global inelastic drift, which is the difference between the preselected target drift $\left(\theta_{\mathrm{u}}\right)$ and the yield $\operatorname{drift}\left(\theta_{\mathrm{y}}\right) ; f_{\mathrm{y}}$ is the nominal yield strength of steel; $\gamma_{\mathrm{p}}$ is the link plastic rotation angle; and $W_{\mathrm{pmc}}$ and $W_{\mathrm{psc}}$ are the required plastic section modulus of middle column bases and side column bases, respectively $\left(n, \beta_{i}, F_{i}\right.$, and $h_{i}$ have been explained previously). Note that no external work done by gravity loading needs to be included. The required link shear strength at any story $i$ can be determined as $V_{i s}=\beta_{i} V_{\text {ts }}$.

The elements outside the shear links, including beam segments, braces, and columns, are performed based on the capacity design approach. It is assumed that the braces can bear whole story shear force and still maintain elasticity. The axial force of braces can then be expressed as 


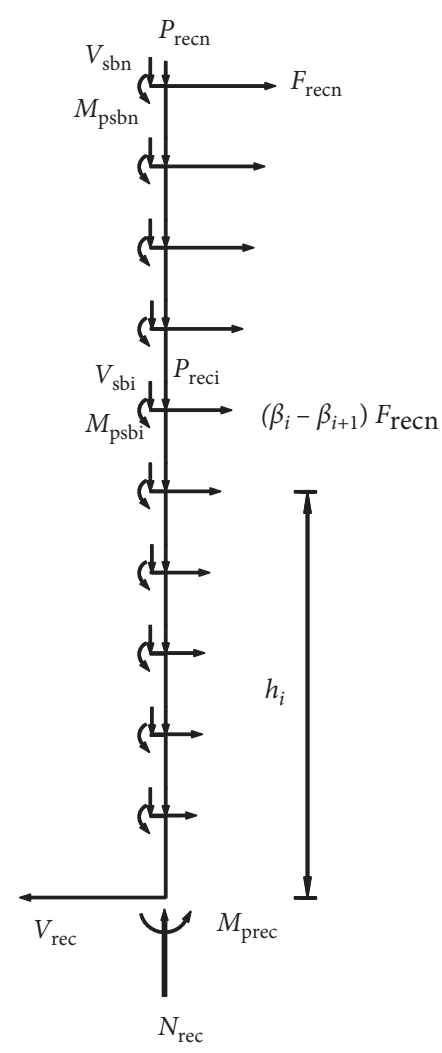

FIGURE 4: Free body diagram of the right exterior column.

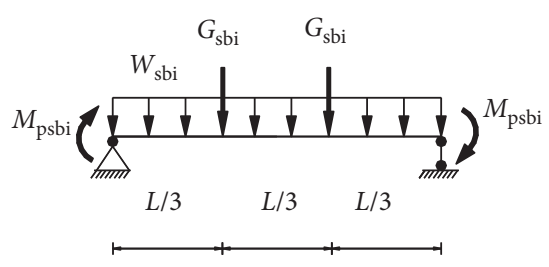

FIGURE 5: Free body diagram of the side span beam.

$$
N_{i}=\frac{V_{i}}{2 \cos \theta_{i}},
$$

where $V_{i}, \theta_{i}$, and $N_{i}$, respectively, are the story shear force, the slope of the brace, and the axial force of braces at the $i$ th story.

Once the plastic link shear forces are determined, the frame can be cut into several free bodies of columns and beam segments, as illustrated in Figures $4-7$. The required strength of these members can be calculated using these free bodies. The required balancing lateral forces applied on some free bodies are assumed to maintain the same distribution as represented by equation (22) and can be easily calculated using the moment equilibrium of these free bodies.

In Figures $4-7, M_{\mathrm{psb} i}$ is the nominal plastic moment of a side beam at story $i ; V_{\mathrm{sb} i}$ is the shear force of the side beam end at story $i ; P_{\text {rici }}\left(P_{\text {reci }}\right)$ is the vertical force resulting from tributary gravity loading at story $i ; F_{\text {ricn }}\left(F_{\text {recn }}\right)$ is the required balancing lateral force that can be regarded as the lateral force sheared by the column at the top ( $n$ th) story;

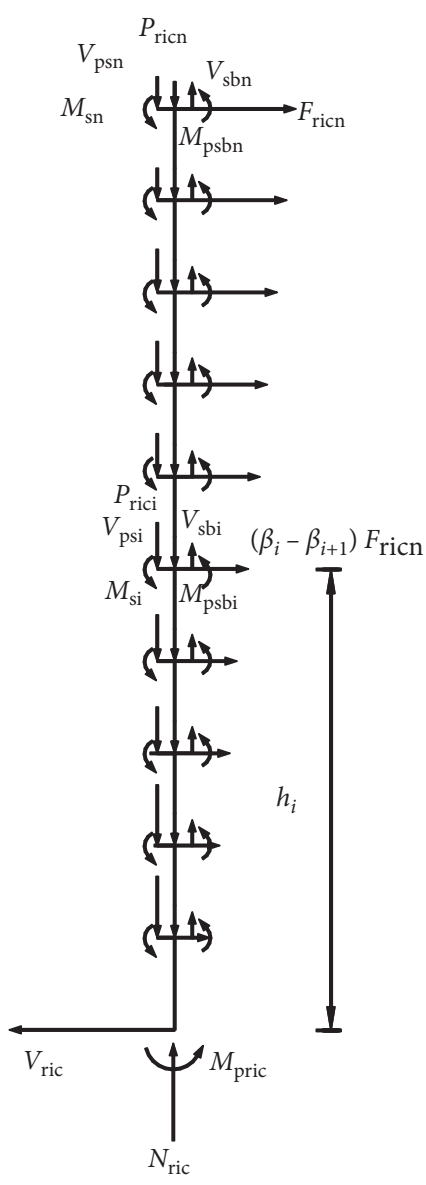

FIGURE 6: Free body diagram of the right interior column.

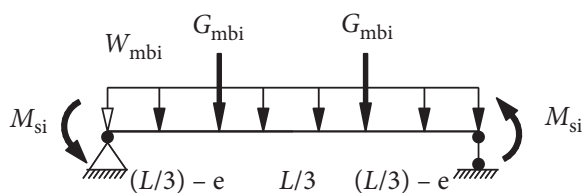

FIgURE 7: Free body diagram of middle span beam.

$N_{\text {rec }}\left(N_{\text {ric }}\right)$ is the axial force at the column base; $V_{\text {rec }}\left(V_{\text {ric }}\right)$ is the shear force at the column base; $M_{\text {prec }}\left(M_{\text {pric }}\right)$ is the nominal plastic moment at the column base; $G_{\mathrm{sb} i}$ and $G_{\mathrm{mbi}}$ are the concentrated loading of the side beam and the middle beam at story $i$, respectively; $w_{\mathrm{sbi}}$ and $w_{\mathrm{mb} i}$ are the uniform distribution loading of the side beam and the middle beam at story $i$, respectively; $V_{\mathrm{psi}}$ is the nominal plastic shear strength of the link at story $i ; M_{\mathrm{si}}$ is the link end moment; and $\beta_{i}$ is the shear distribution factor at story $i$ obtained using equation (20).

The maximum expected force of link shear $\left(V_{\mathrm{u}}\right)$ can be considerably higher than the strength of nominal plastic shear $\left(V_{\mathrm{ps}}\right)$ resulting primarily from material overstrength, strain hardening, and the development of shear resistance in the link flanges. For confining all the inelastic activity to the shear links while keeping the other elements essentially elastic when 


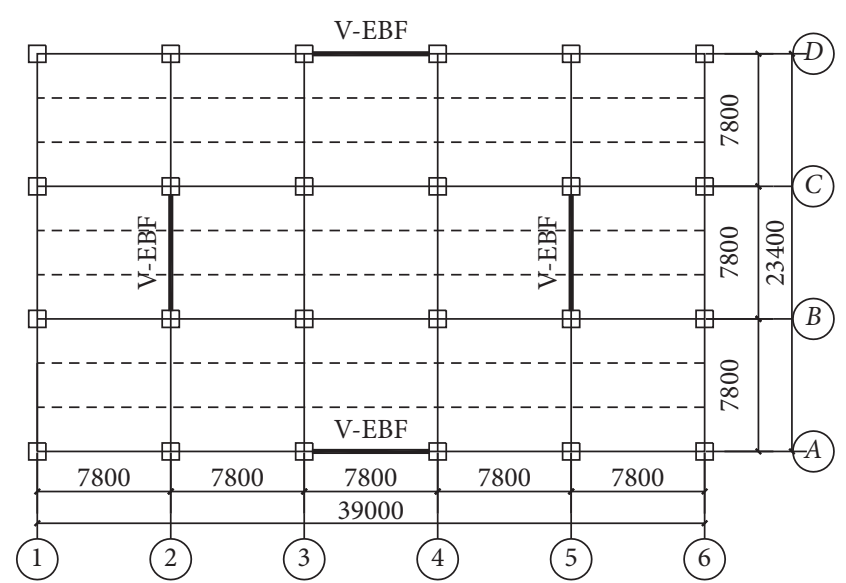

(a)

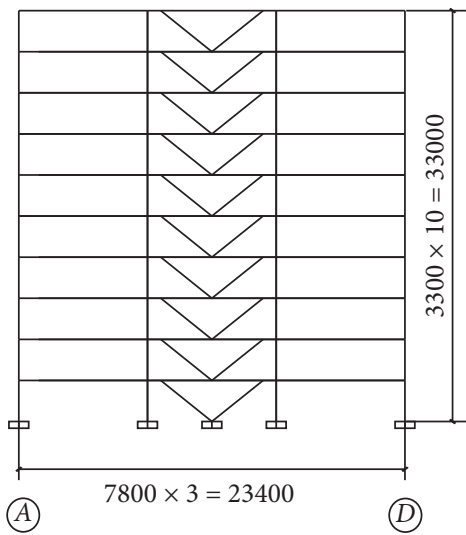

(b)

Figure 8: Structure (a) plane and (b) elevation views (unit: $\mathrm{mm}$ ).

rare earthquakes occur, scale factors should be employed to increase the required strength of the parts outside the links. For beams, columns, and braces, the scale factors are all 1.1. For the scaled strength required, the columns, beams, and braces are designed in accordance with Chinese codes.

(7) Iterate design until convergence: when the difference between $T_{i+1}$ and $T_{i}$ is smaller than $2 \%$, the iteration process can be stopped, where $T_{i+1}$ and $T_{i}$ are the fundamental structural period of $(i+1)$ th and $i$ th iterations, respectively.

An example is presented in the following sections to describe the details of the design process.

3.2. Description of Design Structure. The elevation and plan layout of a 10-story building are shown in Figure 8. The building is located at site group 2 with soil type II, and the design earthquake acceleration amplitude is $0.52 \mathrm{~g}, 2 \%$ of an earthquake with a return period of 50 years. Each member is made of Q235 steel, and the link length is $0.8 \mathrm{~m}$. In Figure 8(a), the dashed lines denote secondary beams, which are hinged to the primary beams.

The vertical loads applied on the V-EBF are calculated on the basis of the corresponding tributary areas. The concentrated force and position are listed in Table 2. The lateral resisting systems consist of two V-EBFs in each direction. Assuming that the total horizontal seismic load is borne by the two V-EBFs, half of the total building mass is lumped at the frame joints given in Table 3.

From Table 2, the sectional dimensions of the beams, columns, and braces of the V-EBFs can be determined preliminarily by using the design software. The capacities of different components are designed as described below.

\subsection{V-EBF Design}

3.3.1. Preselected Plastic Mechanism. According to existing research, the drift ratio $\theta_{\mathrm{y}}$ between two adjacent layers of a structure is 0.003 and the target ductility ratio $\mu$ is set to 3.5 .
3.3.2. Natural Vibration Characteristics of Structure. For ensuring $90 \%$ of mass participation, the first three modes $\phi_{j}$ $(j=1,2,3)$ and periods $T_{j}(j=1,2,3)$ are calculated. The values of $\Gamma_{j}, X_{\text {mas, }, j}$ and $M_{j}^{*}$ are calculated (Table 4$)$ using equations (17)-(19), respectively. Due to limited space, the data in Table 2 and the following sections are of the final iteration.

\subsubsection{Accumulated Hysteretic Energy Demand and Ductility} Ratio of $V$-EBF. The equivalent velocities of the first three modes can be calculated using equations (5)-(9) at $p=$ 0.05 and $\zeta=0.05$. The values $V_{\mathrm{EH}, 1}=1.218 \mathrm{~m} / \mathrm{s}, V_{\mathrm{EH}, 2}=$ $1.355 \mathrm{~m} / \mathrm{s}$, and $V_{\mathrm{EH}, 3}=0.8643 \mathrm{~m} / \mathrm{s}$ are obtained. The accumulated hysteretic energy demand can be determined as $E_{\mathrm{h}(\mathrm{MODF})}=2955.9 \mathrm{kN} \cdot \mathrm{m}$ by using equations (15)-(19).

The accumulated ductility ratio of the V-EBF is calculated as $N E_{\mathrm{h}, \mu}=17.95$ by using equations (11)-(14) with $p=0.05, \zeta=0.05, \mu=3.5, \alpha=1.0$, and $\beta=1.1$.

3.3.4. Shear Link Design. On the basis of the distribution pattern of lateral forces, as shown by equations (20)-(23), and the virtual work principle, as expressed by equations (24)-(28), the required link shear strength at any story $i$ can be determined as $V_{i s}=\beta_{i} V_{\mathrm{ts}}$.

Generally, axial force effects do not need to be considered during shear link design, and the required areas of the link web at any story can be calculated:

$$
\begin{aligned}
& A_{t w} \geq \frac{V_{\mathrm{ts}}}{0.58 f_{\mathrm{y}}}, \\
& A_{i w}=\beta_{i} A_{t w} .
\end{aligned}
$$

The link flanges are the same as the middle beam. The link section should also satisfy the width-thickness limitations and the stiffener requirements provided in Chinese seismic provisions.

3.3.5. Design of Members outside Links. The capacity method suggested in Section 3.1 can be used to design members 
TABLE 2: Vertical load values and positions of the frame.

\begin{tabular}{|c|c|c|c|c|c|c|c|c|c|c|c|c|}
\hline \multirow{2}{*}{ Position } & \multicolumn{6}{|c|}{ Top floor } & \multicolumn{6}{|c|}{ Other floors } \\
\hline & \multicolumn{2}{|c|}{ Exterior columns } & \multicolumn{2}{|c|}{ Interior columns } & \multicolumn{2}{|c|}{ Secondary beams } & \multicolumn{2}{|c|}{ Exterior columns } & \multicolumn{2}{|c|}{ Interior columns } & \multicolumn{2}{|c|}{ Secondary beam } \\
\hline \multirow{3}{*}{$\begin{array}{l}\text { Vertical load } \\
(\mathrm{kN})\end{array}$} & Dead & Live & Dead & Live & Dead & Live & Dead & Live & Dead & Live & Dead & Live \\
\hline & load & load & load & load & load & load & load & load & load & load & load & load \\
\hline & 91.9 & 5.07 & 109.9 & 10.14 & 109.9 & 10.14 & 115.0 & 20.28 & 99.8 & 40.56 & 99.8 & 40.56 \\
\hline
\end{tabular}

TABle 3: Masses at the nodes of the frame.

\begin{tabular}{lcccc}
\hline \multirow{2}{*}{ Position } & \multicolumn{2}{c}{ Top floor } & \multicolumn{2}{c}{ Other floors } \\
& Exterior columns & Interior columns & Exterior columns & Interior columns \\
\hline Mass $(\mathrm{kg})$ & 70744.0 & 106115.8 & 68383.3 & 102575.0 \\
\hline
\end{tabular}

TABle 4: Modal factors.

\begin{tabular}{lcccc}
\hline Mode & $T_{j}(\mathrm{~s})$ & $\Gamma_{j}$ & $X_{\max , j}$ & $M_{j}^{*}(\mathrm{~kg})$ \\
\hline 1 & 1.437 & 1.42 & 0.718 & 1420000 \\
2 & 0.4501 & -0.614 & 0.166 & 1510000 \\
3 & 0.2552 & 0.294 & 0.046 & 1850000 \\
\hline
\end{tabular}

TABLE 5: Member sections of 10-story V-EBF.

\begin{tabular}{|c|c|c|c|c|c|}
\hline \multirow{2}{*}{ Number of stories } & \multicolumn{2}{|c|}{ Column sections } & \multicolumn{2}{|c|}{ Beam sections } & \multirow{2}{*}{ Brace section } \\
\hline & Interior column & Exterior column & Middle beam & Side beam & \\
\hline$\overline{1-2}$ & $\square 650 * 35$ & $\square 400 * 18$ & $\mathrm{H} 550 * 300 * 20 * 30$ & $\mathrm{H} 300 * 300 * 18 * 22$ & $\mathrm{H} 300 * 300 * 16 * 20$ \\
\hline $3-5$ & $\square 600 * 30$ & $\square 400 * 18$ & $\mathrm{H} 550 * 300 * 18 * 24$ & $\mathrm{H} 300 * 300 * 18 * 22$ & $\mathrm{H} 300 * 300 * 16 * 20$ \\
\hline $6-8$ & $\square 450 * 25$ & $\square 400 * 18$ & $\mathrm{H} 500 * 300 * 16 * 20$ & $\mathrm{H} 300 * 300 * 18 * 22$ & $\mathrm{H} 250 * 250 * 16 * 20$ \\
\hline $9-10$ & $\square 400 * 20$ & $\square 400 * 18$ & $\mathrm{H} 500 * 300 * 14 * 18$ & $\mathrm{H} 300 * 300 * 18 * 22$ & $\mathrm{H} 250 * 250 * 12 * 14$ \\
\hline
\end{tabular}

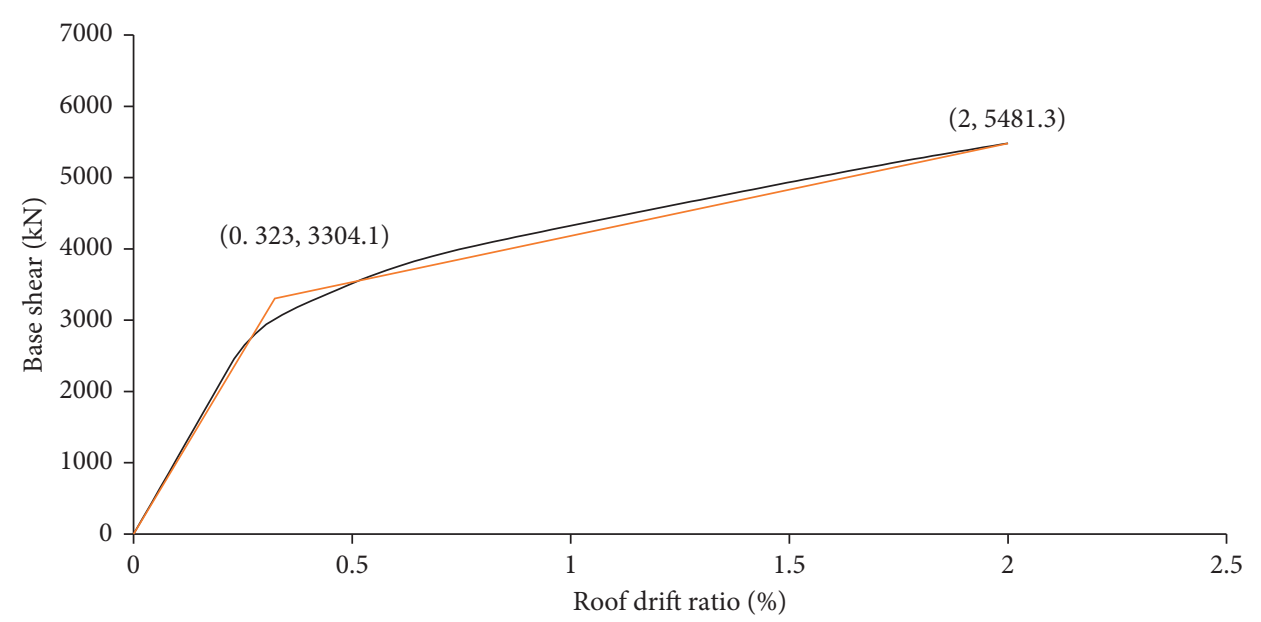

Figure 9: Pushover curve of the 10-story V-EBF.

outside the links. The final member sections obtained after the iterative design process are given in Table 5 .

\section{Performance Evaluation of Designed V-EBF}

To study the performance of the designed $\mathrm{V}$-EBF under rare earthquakes with $2 \%$ probability of being the heaviest in 50 years, both static pushover analysis and time-history dynamic analysis are performed. The evaluation is mainly aimed at illustrating the effectiveness of the proposed design method. For this purpose, both dead loads and half of live loads are placed on the frame during nonlinear static pushover and time-history dynamic analyses, and the seismic masses are lumped at frame joints. The static pushover analysis is conducted using SAP2000, while ABAQUS is adopted for the dynamic analysis.

4.1. Nonlinear Static Analysis Results. By employing the lateral load distribution pattern specified in equations (20)-(22), the frame is pushed monotonically until a roof drift ratio of $2 \%$ is obtained. 


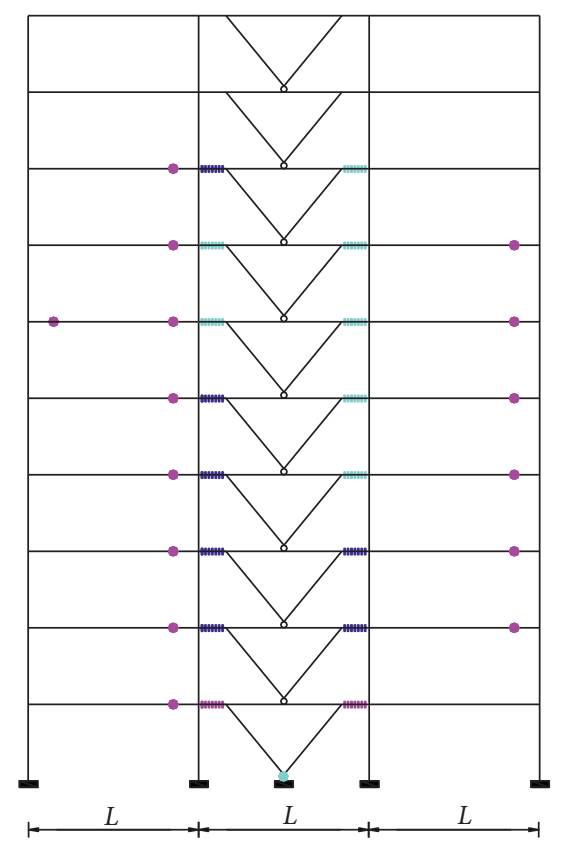

(a)

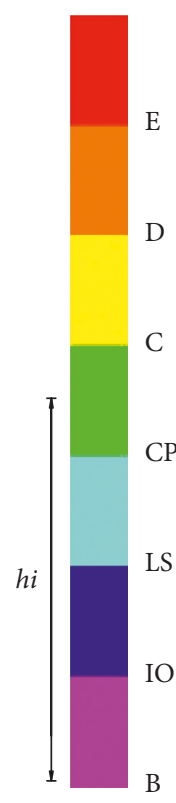

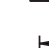

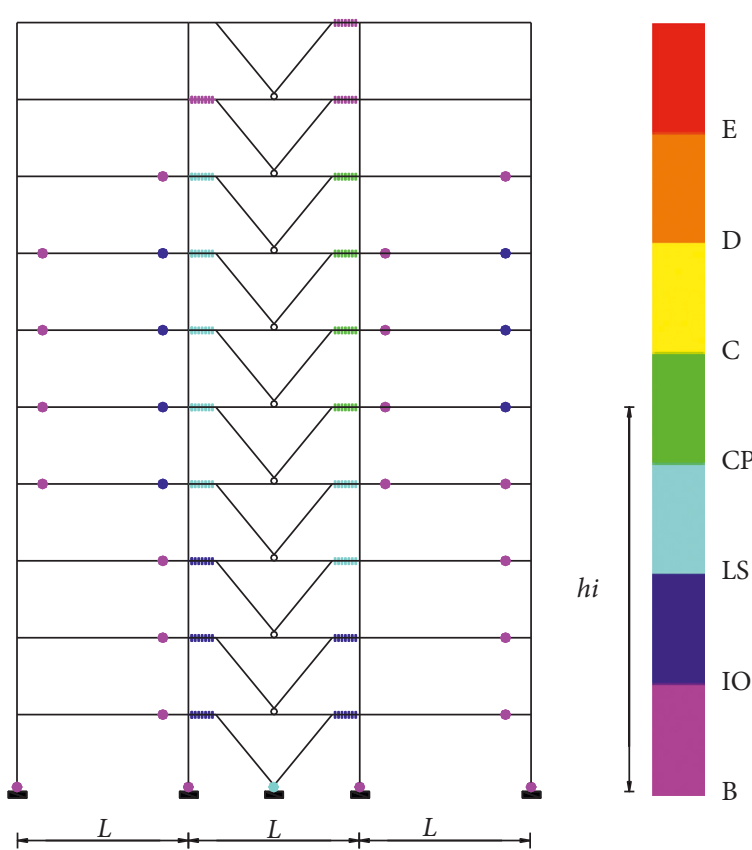

(b)

Figure 10: Inelastic activity of the 10-story V-EBF at a roof drift ratio of (a) 1.05\% and (b) 2\% (冊: yielding in link and e: plastic hinge).

The pushover curve is shown in Figure 9. It shows clearly that the lateral bearing capacity is $3304.1 \mathrm{kN}$ corresponding to the onset of stiffness deterioration, which is $18.1 \%$ larger than that of the design base shear. This may be attributed to the fact that the improved overall lateral resistance ability of the frame is due to the material strain hardening and the development of shear resistance in the link flanges. The ratio of the structural yield drift-the assumed yield drift ratio given in Section 3.3-is approximately $0.3 \%$. Therefore, a $0.3 \%$ yield drift for a 10 -story $\mathrm{V}$-EBF is generally reasonable.

Furthermore, the order of appearance and the location of plastic hinges in the frame are also obtained from the pushover analysis. Plastic hinges first occur at the links, followed by the side beam ends and column bases. Figure 10 shows the quantity and location of plastic hinges when the frame is pushed to roof drift ratios of $1.05 \%$ and $2 \%$, which is almost identical to the prediction made by the preselected yield mechanism.

Clearly, the proposed design method can reliably predict the yield drift, design base shear, and the location of plastic hinges.

4.2. Nonlinear Dynamic Analysis Results. A finite element model is developed for the V-EBF by employing ABAQUS. Moreover, the beam elements (B32) are utilized to simulate the braces, columns, and beams. To capture local instability, the links are meshed with a four-node reduced integration shell element (S4R). Furthermore, both hinged beam-brace connections and rigid beam-column connections are also employed. It is found that the out-of-plane degrees of

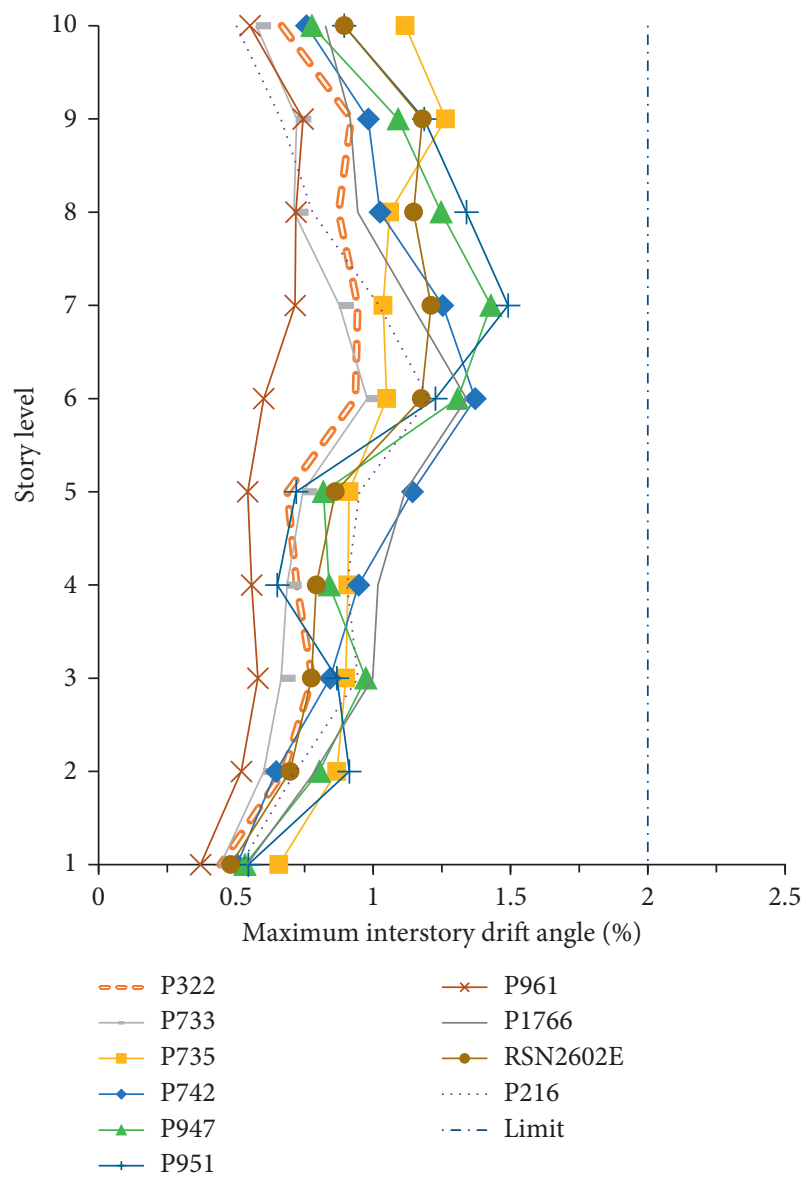

Figure 11: Maximum interstory drift angles of 10-story V-EBF. 


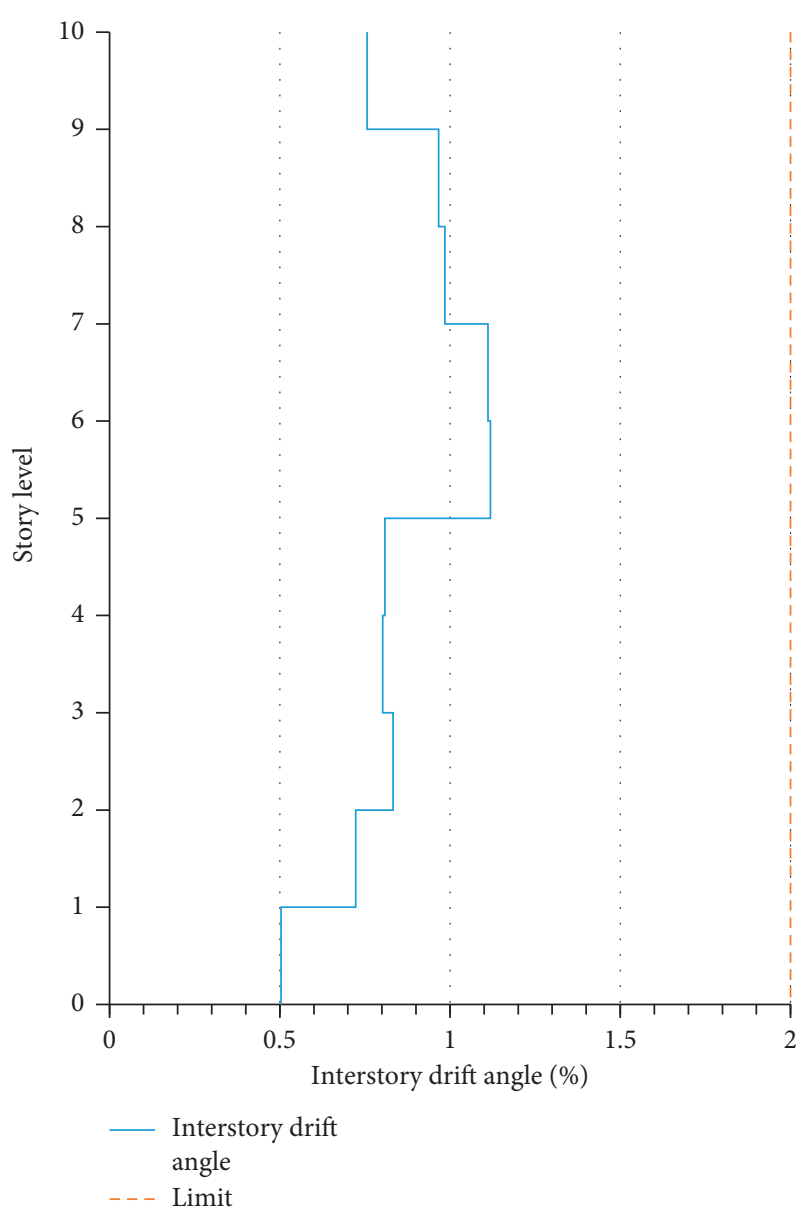

FIGURE 12: The average values of the interstory drift angle under different earthquakes.

freedom of the beam and shell element in the plane frame are restrained.

A total of 10 ground motion records are selected as input earthquakes, and the acceleration amplitudes are scaled to $510 \mathrm{~cm} / \mathrm{s}^{2}$, which corresponds to a rare earthquake. The selected records are strictly required to satisfy the criteria: for each record, it is expected that (1) the ratio of the calculated cumulative hysteretic energy of the structure is not less than $60 \%$ and (2) the mean ratio of all records is not less than $80 \%$.

The average value of total dissipated hysteretic energy of the V-EBF for the 10 records is $2705.3 \mathrm{kN} \mathrm{m}$, which is slightly lower than the design requirement. This result shows that the proposed design method is rather conservative in seismic design.

Figures 11 and 12 show the maximum interstory drift angle profiles and their average values, respectively, under different records. It can be observed in Figure 12 that the interstory drift angles are closer to $1 \%$ preselected target drift, and the frame indicates uniform interstory drift.

\section{Conclusions}

In this paper, a method for the performance-based seismic design of V-EBFs is proposed and validated through nonlinear static and dynamic analyses. The following conclusions can be drawn:

(1) The accumulated ductility ratio spectrum is closely related to the soil type, site group, and structural damping ratio, as well as the ductility and postyield stiffness ratio. However, the effect of the structural period on the accumulated ductility ratio spectra can be neglected. Finally, the mathematical expressions for an accumulated ductility ratio spectrum that is in accordance with the classification of Chinese soil sites can be obtained.

(2) A procedure for the energy-based seismic design of V-EBFs is proposed by employing both hysteretic energy spectra and accumulated ductility spectra, which are applicable in China.

(3) According to the results obtained from pushover analysis, the yield drift, design base shear, and location of plastic hinges coincide with the predictions made by employing the proposed design method.

(4) The performance validation of V-EBFs shows that the preselected yield mechanism and target ductility are reasonable based on the results of the nonlinear static and dynamic analyses. The proposed design method for V-EBFs is rather conservative.

\section{Data Availability}

The data used to support the findings of this study are available from the corresponding author on reasonable request.

\section{Conflicts of Interest}

The author declares no conflicts of interest.

\section{Acknowledgments}

This research was funded by the National Natural Science Foundation of China (Grant no. 51278320) and Natural Science Foundation of Hefei University (Grant nos. 18ZR14ZDA and 15KY01ZD), which are gratefully acknowledged.

\section{References}

[1] G. W. Housner, "Limit design of structures to resist earthquakes," in Proceedings of the 1st World Conference Earthquake Engineering, Berkeley, CA, USA, 1956.

[2] V. Ozsarac, S. Karimzadeh, M. A. Erberik, and A. Askan, "Energy-based response of simple structural systems by using simulated ground motions," Procedia Engineering, vol. 199, pp. 236-241, 2017.

[3] S. H. Chao and S. C. Goel, "Performance-based seismic design of EBF using target drift and yield mechanism as performance criteria," Report no. UMCEE 05-05, Department of Civil and Environmental Engineering, University of Michigan, Ann Arbor, MI, USA, 2005.

[4] S. Leelataviwat, S. C. Goel, and B. Stojadinovic, "Toward performance-based seismic design of structures," Earthquake Spectra, vol. 15, no. 3, pp. 435-461, 1999. 
[5] S. S. Lee, Performance-based design of steel moment frames using target drift and yield mechanism, Ph.D. thesis, Department of Civil and Environmental Engineering, University of Michigan, Ann Arbor, MI, USA, 2002.

[6] S. H. Chao and S. C. Goel, "A seismic design method for steel concentric braced frames for enhanced performance," in Proceedings of the 4th international conference on earthquake engineering, Taipei, Taiwan, October 2006.

[7] S. H. Chao and S. C. Goel, "Performance-based plastic design of seismic resistant special truss moment frames," Report no. UMCEE 06-03, Department of Civil and Environmental Engineering, University of Michigan, Ann Arbor, MI, USA, 2006.

[8] J. Kim, H. Choi, and L. Chung, "Energy-based seismic design of structures with buckling-restrained braces," Steel and Composite Structures, vol. 4, no. 6, pp. 437-452, 2004.

[9] D. R. Sahoo and S.-H. Chao, "Performance-based plastic design method for buckling-restrained braced frames," Engineering Structures, vol. 32, no. 9, pp. 2950-2958, 2010.

[10] B. Akbas, J. Shen, and H. Hao, "Energy appproach in peformance-based seismic design of steel moment resisting frames for basic safety objective," The Structural Design of Tall Buildings, vol. 10, no. 3, pp. 193-217, 2001.

[11] L. Mastrandrea and V. Piluso, "Plastic design of eccentrically braced frames, II: failure mode control," Journal of Constructional Steel Research, vol. 65, no. 5, pp. 1015-1028, 2009.

[12] R. Montuori, E. Nastri, and V. Piluso, "Theory of plastic mechanism control for MRF-EBF dual systems: closed form solution," Engineering Structures, vol. 118, pp. 287-306, 2016.

[13] R. Montuori, E. Nastri, and V. Piluso, "Influence of the bracing scheme on seismic performances of MRF-EBF dual systems," Journal of Constructional Steel Research, vol. 132, pp. 179-190, 2017.

[14] R. Montuori, E. Nastri, and V. Piluso, "Preliminary analysis on the influence of the link configuration on seismic performances of MRF-EBF dual systems designed by TPMC," Ingegneria Sismica, vol. 33, no. 3, pp. 52-64, 2016.

[15] G. Dell'Aglio, R. Montuori, E. Nastri et al., "A critical review of plastic design approaches for failure mode control of steel moment resisting frames," Ingegneria Sismica, vol. 34, no. 4, pp. 82-102, 2017.

[16] G. Dell'Aglio, R. Montuori, E. Nastri, and V. Piluso, "Consideration of second-order efects on plastic design of steel moment resisting frames," Bulletin of Earthquake Engineering, vol. 17, no. 6, pp. 3041-3070, 2019.

[17] H. Choi and J. Kim, "Energy-based seismic design of buckling-restrained braced frames using hysteretic energy spectrum," Engineering Structures, vol. 28, no. 2, pp. 304-311, 2006.

[18] G. H. Sun, Q. Gu, R. Q. He et al., "Performance based seismic design of steel plate shear walls using hysteretic energy spectrum," Journal of Building Structures, vol. 32, no. 11, pp. 126-133, 2011, in Chinese.

[19] H. Choi and J. Kim, "Evaluation of seismic energy demand and its application on design of buckling-restrained braced frames," Structural Engineering and Mechanics, vol. 31, no. 1, pp. 93-112, 2009.

[20] S. B. Kharmale and S. Ghosh, "Performance-based plastic design of steel plate shear walls," Journal of Constructional Steel Research, vol. 90, pp. 85-97, 2013.

[21] E.-G. Xiong, H. He, F.-F. Cui, and L. Bai, "Energy-based response of simple structural systems by using simulated ground motions," Periodica Polytechnica Civil Engineering, vol. 60, no. 1, pp. 127-134, 2016.
[22] M. G. Mezgebo and E. M. Lui, "A new methodology for energy-based seismic design of steel moment frames," Earthquake Engineering and Engineering Vibration, vol. 16, no. 1, pp. 131-152, 2017.

[23] M. Bruneau and N. Wang, "Some aspects of energy methods for the inelastic seismic response of ductile SDOF structures," Engineering Structures, vol. 18, no. 1, pp. 1-12, 1996.

[24] C. C. Chou and C. M. Uang, "An evaluation of seismic energy demand: an attenuation approach," PEER Report 2000/04, Pacific Earthquake Engineering Research Center, College of Engineering, University of California, Berkeley, CA, USA, 2000.

[25] C. L. Ma, Q. Gu, and G. H. Sun, "Mathematical expression of design hysteretic energy spectra based on Chinese soil type," Mathematical Problems in Engineering, vol. 2019, Article ID 3483516, 10 pages, 2019.

[26] A. Teran-Gilmore, E. Avila, and G. Rangel, "On the use of plastic energy to establish strength requirements in ductile structures," Engineering Structures, vol. 25, no. 7, pp. 965-980, 2003.

[27] C.-C. Chou and C.-M. Uang, "A procedure for evaluating seismic energy demand of framed structures," Earthquake Engineering \& Structural Dynamics, vol. 32, no. 2, pp. 229244, 2003. 


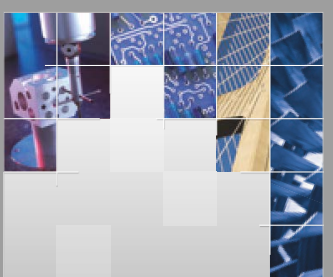

\section{Enfincering}
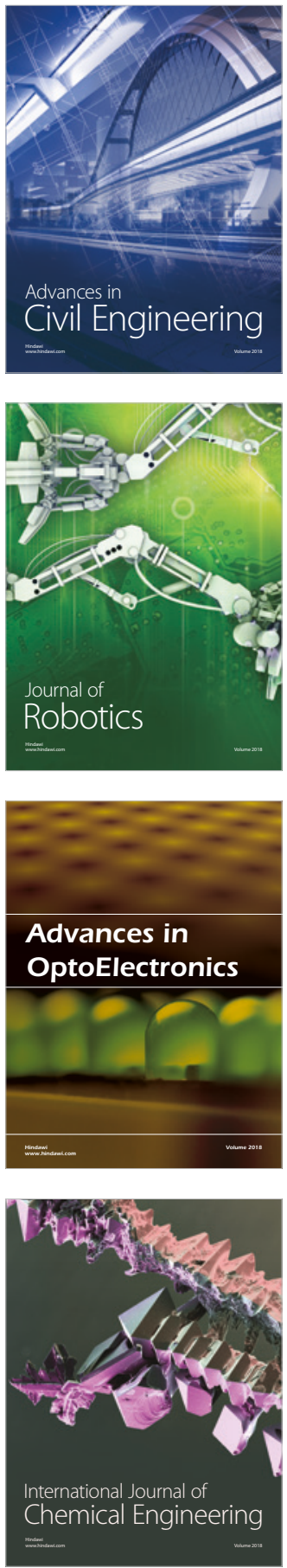

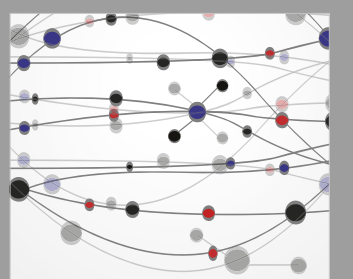

\section{Rotating \\ Machinery}

The Scientific World Journal

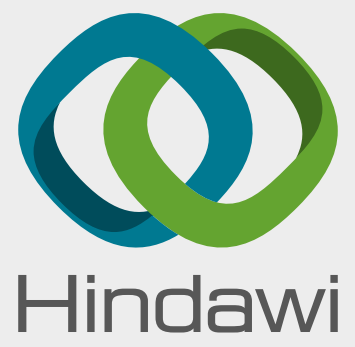

Submit your manuscripts at

www.hindawi.com
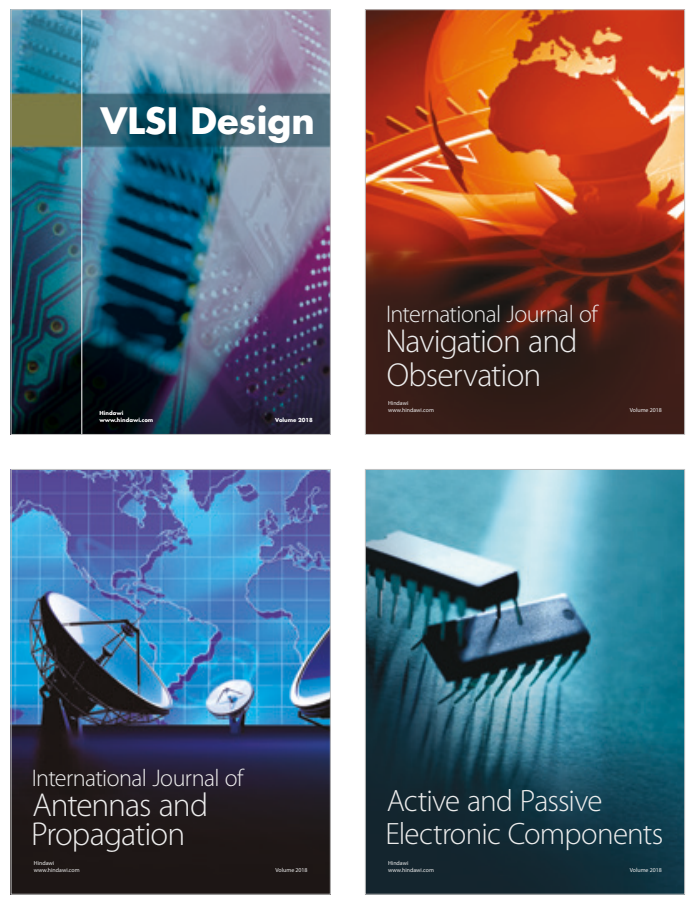
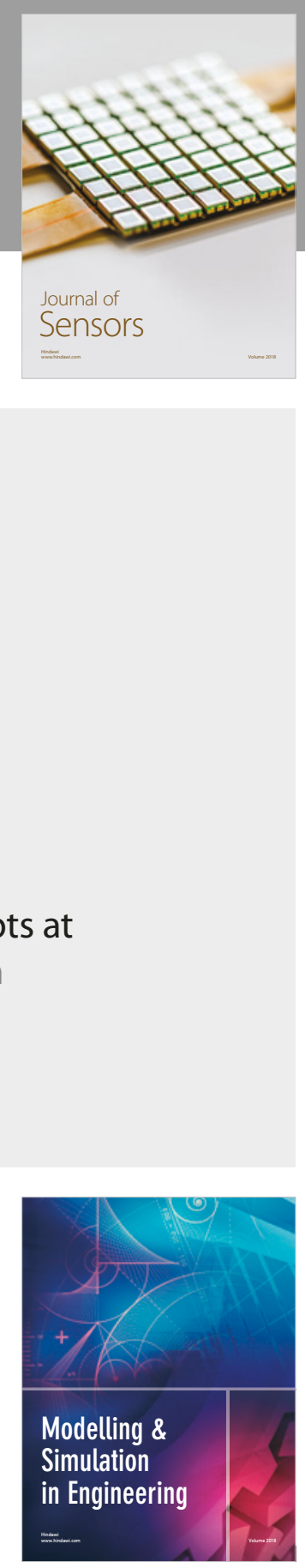

\section{Advances \\ Multimedia}
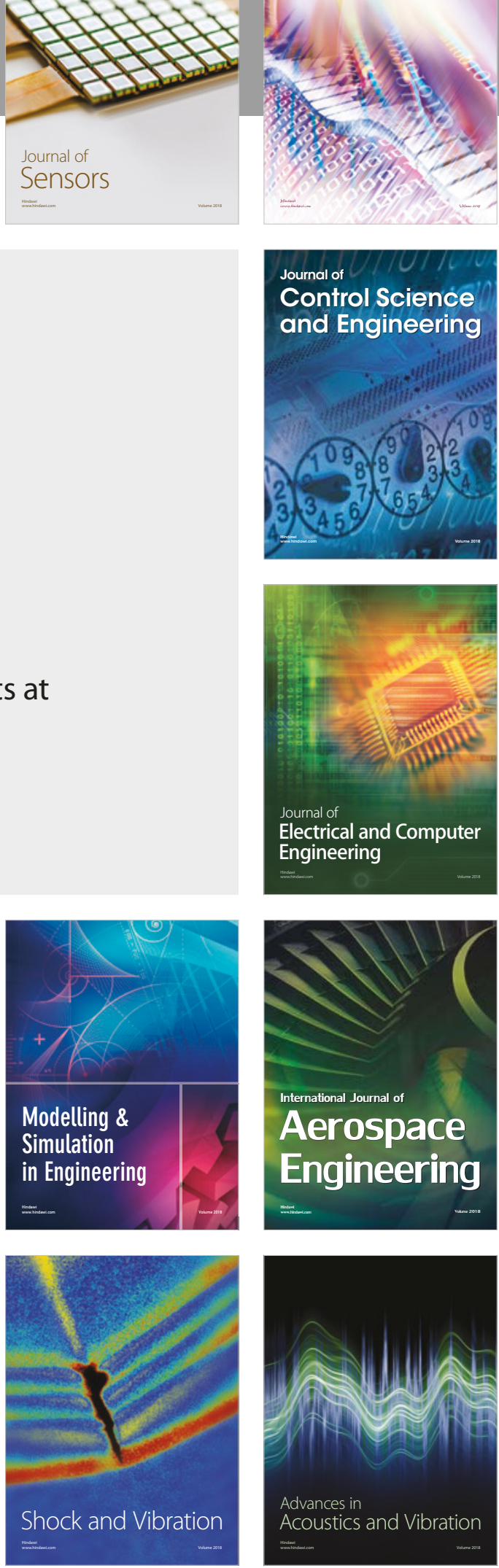